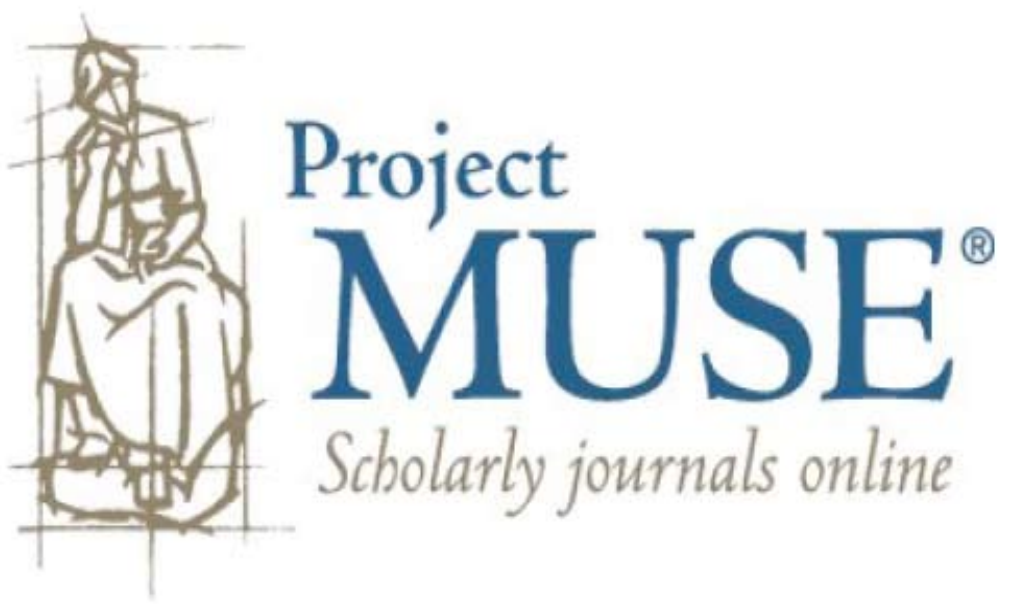




\title{
The Problem of Empathy: Medicine and the Humanities*
}

\author{
Rebecca Garden
}

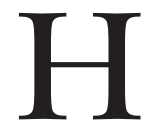

EALTH CARE INSTITUTIONS and medical educators assert that empathy is essential to optimum patient care, yet medical education and the practice of medicine often neglect empathy in favor of biomedical approaches to disease and injury. This essay discusses the development in medical literature of the concept of "clinical empathy"-which attempts to reorient a biomedical, disease-centered approach to treating illness by accounting for an increasing fluency within the interpersonal relations between physician and patient-and examines arguments for supplementing medical training with the study of literature and the practice of reflective writing as a means of developing empathy in physicians. In order to interrogate the problems as well as the possibilities of clinical empathy, I turn to theories of sympathy produced in the eighteenth century, when innovations in medical technology and knowledge had only begun to create separate categories that would ultimately untwine the body from mind and culture. The eighteenth century was also a time when philosophy and literature, rather than being compartmentalized from medicine as distinct disciplines, informed medical understandings before medicine became specialized as a "science." A critical approach to the theory and literature of the eighteenth century can help to formulate a productive critique of clinical empathy in contemporary medicine and to suggest possibilities for a reconfigured and strengthened understanding of empathy within the larger social context of institutions, systems, and access to care.

\section{The Contemporary Debate}

The ongoing debate in medical education and in clinical practice about the importance of empathy illustrates a divided approach to patient care. Those who argue for empathy (or at least for concern for the patient's sociocultural and personal experience of illness) are countering what is

* Thanks to Ilka Datig and Eli Braun for their research assistance. 
seen as a predominantly biomedical approach. This divide is often characterized as disease-centered care versus patient-centered care. The debate about whether disease and pathology are alone responsible for illness and disability or whether (and how much) physicians should focus on the patient's experience of illness unfolds on different levels of discourse and learning. While medical schools, professional organizations, and journal articles advocate empathy in patient care, the practice in hospital wards and clinics often contradicts or undercuts that commitment, emphasizing scientific knowledge at the expense of symbolic and affective aspects of illness. (It is widely acknowledged that the role modeling of senior physicians in clinics and wards has far more influence on trainees than does institutional advocacy or classroom instruction. $)^{1}$

Those physicians and medical educators who advocate empathy in the patient-physician encounter often cite studies suggesting that physicians who engage empathically with patients increase not only the patient's sense of "satisfaction" but also patient compliance with therapeutic regimens and increased physiological well-being. ${ }^{2}$ Physician Howard Spiro echoes both psychological studies and anecdotal perceptions suggesting that medical students begin their training with "a cargo of empathy" that is then displaced when "we teach them to see themselves as experts, to fix what is damaged, and to 'rule out' disease in their field." ${ }^{3}$ Spiro views cadaver dissection, the emphasis on basic science, and the primacy of medical imaging as dangerously objectifying the patient. ${ }^{4}$

While many in medicine agree that empathy needs to be taught and practiced, there is not yet consistency and clarity in the medical literature about what empathy is and how it works. Some physicians discuss empathy casually, without clearly defining it, as in Jerome Lowenstein's essay "Can You Teach Compassion?" ${ }^{5}$ Others define it haphazardly, making use of aesthetic and psychological definitions interchangeably. For example, Spiro supplements a definition from Scribner's Dictionary of the History of Ideas with brief mentions of Freud, Buber, Jung, and even John Donne. ${ }^{6}$ Still others cite psychology, psychoanalysis, and aesthetic theory to historicize and deepen their definitions of clinical empathy. All too often, discussions of empathy in the clinic do not engage with earlier formulations of it in the medical literature. However, some of its proponents have made good use of psychological studies of empathy. The most rigorous of these approaches address empathy as a faculty that involves both feeling and reason. For example, in describing the language physicians should use with patients in order to "build empathy," John L. Coulehan and his co-authors follow psychological models employing both cognitive and emotional components. They go further than authors who see empathy primarily as a benefit the physician bestows upon the patient by insisting that empathy is a collaboration with the patient that 
involves an "action component": physicians must "check back" with patients to confirm or to correct their shared understanding. ${ }^{7}$

Physicians Jochanan Benbassat and Reuben Baumal describe empathy as a "multiple-phase process" that begins with insight into the patient's "concerns, feelings, and sources of distress," followed by "discomfort" that the patient's distress produces in the physician, and then, importantly, by a "desire to remove the cause of distress or at least alleviate it." Benbassat and Baumal not only emphasize the significance of acting to relieve the distress of the other, they also recognize that "each of these steps has mediating variables that influence whether empathy progresses or an alternate terminal point is reached." ${ }^{9}$ This definition makes clear that physicians may experience a kind of empathy without feeling compelled to alleviate distress; this passive response is better understood as emotional resonance. Ethically speaking, empathy is incomplete when it does not lead to an "attempt to help." Benbassat and Baumal caution that doctors must not fail to "progress" from psychological engagement to material aid, and they warn that the insights provided by such psychological engagement may also be used "to harm or manipulate."10 Less activist physicians may see the end point of empathy as a satisfied, retrospective awareness of simply having cared.

The persistent objection to empathy in medical culture derives from the now decades-old arguments in the literature voicing the concern that empathy interferes with scientific and medical objectivity. Jodi Halpern, a psychiatrist with a doctorate in philosophy, offers the most complex and thorough response to such arguments. Her book From Detached Concern to Empathy: Humanizing Medical Practice rejects the dominant medical concepts of "neutral empathy" and "detached concern" as constructed by outdated early twentieth-century preoccupations with scientific objectivity and truth. Halpern draws on psychoanalytic concepts to support her claim that practitioners are inevitably "sympathetically immersed" when making decisions about patients. What practitioners need, according to Halpern, are the skills to use their emotional responses for therapeutic impact. ${ }^{11}$ Arguing that in the "interpersonal realm emotions are crucial for understanding reality," Halpern crafts a complex understanding of clinical empathy that is partly cognitive and partly grounded in "emotional reasoning," that is, an awareness of one's associations and emotional resonances as cues to understanding the "particular meanings that a symptom or a diagnosis has for an individual." 12 The physician uses that emotional awareness imaginatively to understand the patient's experience. Halpern thus redefines empathy as incorporating emotion into a reasoned understanding of a patient's experience as a prelude to therapeutic intervention. (Neuroscientist Michael Gazzaniga's work on new brain imaging studies supports the role of emotions in moral 
reasoning. These studies suggest that when someone is willing to act on a moral belief, it is because the emotional part of the brain has become active when the moral question is considered; similarly, when someone decides not to act on a moral question, it is because the emotional part of the brain does not become active. ${ }^{13}$

The question for many medical educators remains whether empathy, no matter how valuable or how carefully reconfigured, can be taught. Halpern suggests that practitioners can develop clinical empathy through self-education and self-awareness; others suggest various approaches for teaching it to medical students. Lowenstein, a nephrologist, suggests that empathy be taught like other practice-oriented aspects of medicine. He sees an opportunity for teaching empathy in the "case presentation," where students and interns see patients at the bedside and "present the case" to the senior physician by describing the patient's medical history, diagnosis of the current illness, and suggested treatment. Typically case presentations are shorthand recitations of the objective "facts" of the patient's illness and contributing factors, such as obesity and alcohol or tobacco use, often without regard for how the patient might feel about being objectified in terms of addiction and disease. Lowenstein sees case presentations as opportunities for clinicians to teach students empathy by encouraging them to describe patients more fully as persons with intersecting social, psychological, and medical histories, rather than reductively and disparagingly in terms of disorders, addictions, and disease. ${ }^{14}$

Many physicians and other medical professionals advocate training students and practitioners in empathy through the study of literary texts and narrative techniques, an approach described as "literature and medicine" or medical humanities, and practiced by PhDs in English teaching in medical schools or by MDs with some training in literary studies and/or creative writing. This approach at its most sophisticated insists on a complex understanding of the crucial role that narrative and metaphor play in framing social and ethical aspects of health care. It recommends interdisciplinary engagement as an indispensable means of bridging the "bifurcations" of the sciences and humanities, expressed in such conventional dualisms as hard data versus soft data, knowledge versus opinion, fact versus value, and cognition versus affect. ${ }^{15}$ Some physicians and literature and medicine scholars recommend "reflective writing" as a means of encouraging medical students and health care practitioners to understand patients' experiences. Some of this writing can be understood as an exercise in projection rather than reflection. In some schools, for example, first-year medical students interview a patient and then write a medical history from the patient's perspective. The exercise is designed to "elicit" the "story of a patient's life and circumstances" and to help physicians "to establish the appropriate stance 
from which to regard the patient" and to know "where a patient is coming from." 16 This exercise raises questions that are central to the problem of empathy. What part, if any, of a narrative that is written as if it were the patient's perspective accurately represents the patient's point of view if the narrative is written by a medical professional? What measures, if any, are taken to ensure that the narrative is written in collaboration with the patient and is not simply a practitioner's projection and appropriation of the patient's life-story, another kind of mastery of discourse over which the professional assumes authority? The physician is, after all, "regarding the patient," a phrase that appropriately conjures Foucault's articulation of the clinical gaze. How do such exercises in empathy represent the patient's difference or (if it is possible within the institutional discipline of medicine) a counter-gaze?

The problem of empathy begins with the preoccupation with self that obscures the other. Empathy depends on the experiences and imagination of the person who is empathizing, and this dependency has the potential to obfuscate or exclude the patient's suffering and the meaning the patient makes of suffering. A related problem arises with affinity, the way empathy is more likely to occur when the object of empathy resembles the practitioner. Eric Larson and Xin Yao acknowledge that most find it easier to empathize with persons "who are like themselves," and yet they do not further address problems that could be created by the link between empathy and affinity. ${ }^{17}$ Theories of clinical empathy must account for the way that recognizing the patient as like oneself or seeing the patient as "other" factors into both the emotional and cognitive components of empathy. Howard Spiro assumes that the patient's difference is a kind of knowledge that physicians are capable of mastering with modest effort: "Training in continuing care will be of little value without doctors who know something of the life of the people whom they serve; who can empathize with immigrants from Asia and Mexico, with the southern or ghetto experience; and who knew of the Holocaust and of communist oppression." 18 Physicians and trainees, however, should be cautioned that "knowing something" of other cultures and peoples does not mean knowing a particular person's experience of illness. In fact, this kind of knowing should supplement the awareness that it is impossible to fully know another's experience. Physicians who learn about the cultural and social factors that condition their patients' health and compliance with treatment regimens will provide better health care, as long as they work with the patients themselves to learn about the accuracy of their assumptions. In other words, physicians should suspend, even if briefly, their role as experts in order to encourage patients to speak for themselves about their experiences of illness and its meanings. 
Jodi Halpern sees physicians' and patients' different cultural backgrounds as a motivation for, rather than a significant challenge to, clinical empathy. She recognizes that physicians have "inadvertent prejudices toward people with values and backgrounds distinct from their own." The solution for Halpern is for physicians to develop "tolerance and empathy for patients from diverse backgrounds." ${ }^{19}$ Tolerance and empathy, however, are not identical. Tolerance implies co-existing realities rather than the ideal of a reality that is shared empathically by clinician and patient. While tolerance may not ameliorate the power imbalance in the patient-physician encounter, neither does it obscure it through an imagined affinity.

It is worth exploring the problems with empathy that entangle Halpern, who ranks among its most thoughtful proponents, since difficulties in her careful account suggest dilemmas that need to be recognized and resolved if the practice of clinical empathy is to be truly ethical. Halpern's theory of empathy rightly illuminates the interpersonal aspects of the clinical encounter and advocates physician self-awareness. However, it needs to be more clearly situated within the social context of medicine, a context that determines the patient-physician power differential. She acknowledges difficulties inherent in the social arrangements of "health care systems that routinely under-serve the poor." ${ }^{20}$ Her emphasis on the subtleties of empathy, however, diverts attention from power imbalances that contribute to inequities in care. For example, Halpern often illustrates her points with anecdotes from her medical experience (which she describes as "cases," thus drawing rhetorically on the presumed scientific objectification of individual experience), and her configuration of such clinical "cases" reiterates the power of the physician to be empathic. Whether physicians err in understanding and thus treating the patient (as Halpern candidly describes in analyzing her own missteps as a psychiatrist) or whether they use empathy to achieve her ideal of a "full, as well as accurate, understanding of a patient's problems," physicians hold the power of interpretation that determines outcomes for sick patients. Halpern gives an example of her own mastery of this full understanding of patients in her dramatic narration of breaking though to a distressed and distrustful patient through empathy: "As I spoke he turned to look directly at me with tears in his eyes, and we began to work together." In this narrative, the physician is clearly in control of the empathic encounter as well as shaping the interpretation of the story. One wonders if this is how the patient would have written it.

Elsewhere Halpern distinguishes between "fully imagining" the experience of the patient and merely projecting onto the patient. She acknowledges that the physician's imagined experience of the patient may be inaccurate and in need of ongoing dialogue, but she does not doubt 
that such accuracy is possible. Moreover, she asserts that the "guiding intention of empathy is to grasp the situation of another person." 22 Despite these significant, if muted, qualifications, however, Halpern's definition of clinical empathy situates the patient's experience squarely within the realm of the physicians' expertise. ${ }^{23}$ Where some might caution physicians against assuming that they can fully understand the experience of patients, Halpern argues that physicians should imagine "how it feels to have a certain illness, disability, or psychological injury." Recommending that physicians use pronouns such as "I" and "he" interchangeably, Halpern enables appropriation of the patient's experience through subject positions. ${ }^{24}$ (Similarly, Spiro claims that empathy is evident when "I and you' becomes 'I am you,' or at least 'I might be you.'”25) Halpern argues that empathic understanding is more like the "first-person experiential knowledge of an agent anticipating her own acts than it is like the thirdperson predictions of an observer." ${ }^{26}$ Her articulation of the distinction between the necessary imagining of a patient's experience and what would amount to an appropriation of that experience is too nuanced to avoid misunderstandings. It neglects where it should emphasize that the patient experience is difficult to understand because it is beyond the physician's mastery. In regards to the experience of pain and illness, the patient rather than the physician is the expert.

The problems of empathy surface in the very sophistication and complexity of Halpern's argument. That complexity is a welcome correction to the lack of clarity and consistency in other accounts, but in elaborating the subtleties of physicians resonating emotionally with patients in order to recognize the meaning of their suffering, Halpern subverts the important issues of the power differential in the patient-physician encounter and the alterity of the patient's experience. The problems are compounded in an abbreviated version of her argument published in the Journal of General Internal Medicine (JGIM), an article that Halpern describes as geared toward the "busy physician reader." 27 While she professes that the "whole point of empathy is to focus attention on the patient," Halpern's emphasis on moving past "detached concern" and her condensed definition of clinical empathy obscure rather than stress patients' authority over their own experience. By focusing her physician readers' attention on emotional self-attunement and imagining "what it feels like to experience something," that is, what it is like to be the patient, Halpern obscures the patient. ${ }^{28}$ The fact that she composes her JGIM article to persuade the task-oriented and likely skeptical reader-describing " 4 ways that physicians can capitalize on their emotional responses" and how "resonance offers short cuts"-suggests that empathy can be reduced to a pragmatic formula. Her book, on the contrary, suggests that clinical empathy must be understood as complex and nuanced in 
order to be practiced ethically. Neither book nor article sufficiently addresses the economic, political, and cultural factors that determine both physician power and patient needs.

\section{Sympathy in the Eighteenth Century}

While the term empathy (and its German precedent einfühlung) derive from early twentieth-century psychoanalytic and aesthetic theory, the term has a deeper history in the theories and practices of sympathy, and in the related concept sensibility, developed in the eighteenth century. A step back to examine theories of sympathy, developed when science and the humanities were not yet opposed as disciplines, illuminates problems inherent in empathy as it is configured in contemporary medical knowledge and practice. While the humanist practices of eighteenth-century authors and physician-writers obviously cannot serve as a model for twenty-first-century practitioners and their patients, they allow us to imagine a different set of disciplinary relations than exist at present among literary studies, cultural theory, and biomedicine. In the eighteenth century, medicine, philosophy, and literature evolved as interrelated discourses producing a theoretical matrix of understanding that integrated body, feeling, and mind. This matrix developed as the ancient and increasingly archaic humoral theory gave way to late-eighteenth-century theories of sensibility.

Helen Deutsch and John Mullan detail the interdependencies of eighteenth-century medicine and literature-including a shared preoccupation with disease and the body—which Deutsch describes as a "mutual identification of authors and doctors." ${ }^{29}$ Literature and medicine were intertwined through the overlapping cultural work of medical texts, theories of the sublime and sensibility, and the novel of sentiment. Notions of the sympathetic or sensible interrelation of body, feeling, and mind were developed in medical treatises, and theories of sympathy and sensibility are set forth in the philosophical writings of Edmund Burke, David Hume, and Adam Smith, and in novels of sensibility, such as those by Samuel Richardson, Laurence Sterne, and Henry Mackenzie. ${ }^{30}$ What preoccupied those writing on sensibility was the contradiction of an ideal of an extreme sensitivity that also holds the potential to be debilitating, a contradiction suggestive of the contemporary concern that clinical empathy, while greatly valued, can also lead to a physician's disabling overidentification with the patient. ${ }^{31}$

Medical technology in the eighteenth century could do relatively little for the sick or injured patient. Consequently, the social aspects of medical practice bore much of the weight of prevention, treatment, and cure 
and influenced theories of suffering and empathy. ${ }^{32}$ Health and illness were understood in terms of interrelations among the body, the mind, and feeling, as reflected in the eighteenth-century concept of a person's constitution - a term used to describe general health and vitality as integrated with the condition of the mind, disposition, and temperament. ${ }^{33}$ The idea of constitution was foundational to humoral theory, which related health to the balance of bodily fluids, a theory current in the late eighteenth century despite the emergence of modern experimental physiology, developments in disease theory, and other medical advances that superseded humoral theory scientifically but not culturally. The perseverance of humoral theory even into the nineteenth century alongside increasingly common disease-centered practices, such as smallpox inoculation, may be explained by its foundation in an integrated economy of body, feeling, and mind. Medical educators and practitioners today are mirroring the perspective of humoral theory in seeking to reintegrate body, emotion, and mind, as well as in attempting to establish an equilibrium in which scientific knowledge exists in relation to cultural, social, and psychological understandings of the body.

Sensibility, a concept that similarly expresses the interconnectedness of body, affect, and mind, was seen as an integration of physiological sense perception with emotional sensitivity and with reason. The Encyclopaedia Britannica in 1797 describes sensibility as "a nice and delicate perception of pleasure or pain, beauty or deformity" that "seems to depend upon the organization of the nervous system." ${ }^{4}$ Significantly, perception and the body are linked with aesthetics, as "beauty or deformity" align with pleasure and pain. Indeed, the integration of bodily perception with aesthetic experience found a basis in medical treatises on the nervous system, such as Robert Whytt's 1751 Essay on the Vital and Other Involuntary Motions of Animals. Whytt saw the soul as integrated throughout the body, and his developments in understanding the nervous system as a faculty comprised of attributes of both body and mind (along with the work of William Cullen, the younger Alexander Monro, and John Gregory) asserted the unity of body and mind in opposition to Cartesian dualism. ${ }^{35}$ Whytt's claims established a physiological basis for the work of eighteenth-century Scottish moral philosophers, who advanced a social understanding of sympathy as an innate moral sense that is part instinct, part affect. ${ }^{36}$ The individual body, through its "sympathetic" physiology, became in effect a model for the social body. Eighteenth-century sympathy is similar to modern-day empathy in that a feeling of distress for another's suffering motivates the social response, the act of relieving that suffering. (David Hume and Edmund Burke also describe the "pleasure" or "delight" that is a physically felt moral approbation accompanying benevolent actions.) What is different is the way that eighteenth-century 
philosophers perceived sympathy as a hard-wired system that transmits the "sentiments" of one person to another as physically felt sensations. Further, Hume and another philosopher concerned with sympathy, Adam Smith, believed that people's bodies predetermined their ability to sympathize (laborers and "savages" were relatively insensible to physical pain and therefore incapable of sympathy).

The eighteenth-century model of physiologically based sympathy as an innate partaking of another's suffering (at least for those refined enough to feel deeply) brought with it anxiety about collateral harm. In their analyses of sympathy, eighteenth-century thinkers such as Burke and Hume struggled with one frightening aspect of it, the potentially harmful experience of sharing too completely in another's suffering, much as modern medicine struggles with concerns about overidentification and lost objectivity in theories of clinical empathy. Both Burke and Hume argued for mediating pain through representations of suffering in literature and visual art as a means of generating sympathy. ${ }^{37} \mathrm{~A}$ modernday parallel to Burke and Hume's arguments is the claim put forth by literature and medicine scholars that the study of literature is a means of engaging with suffering without being overwhelmed by it. This claim should address the same questions about the ethicality of that aesthetic distance as those raised by criticisms of eighteenth-century practices of mediation.

Claudia Johnson critiques the tendency in eighteenth-century sentimental literature to reduce its subjects, usually females in distress, to spectacles of suffering in order to exercise the moral sympathy of the elite male onlooker. Johnson illustrates this mode of sympathy (as selfgratifying pity rather than Hume's and Burke's social sympathy) with an example from Burke's Reflections on the Revolution in France, where Burke "cries again and again, not over Marie-Antoinette herself, who bears her sorrow like a Roman, but rather over the 'description' of her which he himself has wrought." ${ }^{8}$ Johnson's criticism suggests that it is possible to manipulate an encounter with suffering in ways that are ultimately, even if unknowingly, self-serving. This same challenge must be made to those in medical humanities who assert that the study of literature and the production of reflective writing necessarily provide a "grounding for empathic attention to patients." ${ }^{39}$ Does the empathy one feels when reading literature necessarily lead to greater empathy in the clinical setting? Physicians sensitive to ethical problems in literary texts are not necessarily sensitive to ethical problems in the clinic. Johnson's (and others') critiques of sympathy remind us that clinicians who read literature as imaginative mediation, or as a means to understand the experience of real-life patients, must beware of tendencies to aestheticize illness in ways that subtly discount a patient's suffering while according physicians the comfort of fictive distance. 
The theory of sympathy and sensibility that most fully addresses the limits of an imaginative response to illness and suffering is found in the work of Adam Smith, a key thinker in eighteenth-century Scottish moral philosophy. ${ }^{40}$ Influenced by physicians Whytt and Cullen, Smith describes sympathy as produced by the nervous system in response to the spectacle of another's pleasure or pain. ${ }^{41}$ While this is an innate physiological process, the degree of feeling is mediated not only by the body but also by the imagination. In his Theory of Moral Sentiments (1759), Smith both asserts and qualifies an imaginative identification with suffering. It is the imagination, he writes, that allows us to place ourselves in the situation of the sufferer: "we conceive ourselves enduring all the same torments, we enter as it were into his body, and become in some measure the same person with him, and thence form some idea of his sensations and even feel something which, although weaker in degree, is not altogether unlike them." ${ }^{42}$ Smith qualifies identification with the sufferer, seeing it as the same in kind but not in degree. The ethics of sympathy, for Smith, depend on the ability to imagine the suffering of another, and the imagination both enables sympathy and enforces its limit: "We have no immediate experience of what other men feel; we can form no idea of the manner in which they are affected, but by conceiving what we ourselves should feel in the like situation." ${ }^{33}$ He further qualifies the limits of sympathy by addressing its mediation in literature, arguing that while we sympathize with suffering in novels, that sympathy is far different from actual human suffering.

In suggesting another limit to the power of sympathy in the face of suffering, Smith raises a further concern for clinical empathy. Socially determined responses to suffering, such as disgust, often overcome feelings of sympathy: "Violent hunger, for example, though upon many occasions not only natural, but unavoidable, is always indecent, and to eat voraciously is universally regarded as a piece of ill manners." ${ }^{44}$ Disgust, a product of socialization (what Smith calls manners), outweighs sympathy in this instance. While Smith consciously articulates one limit of sympathy-the way in which it is socially constructed-his work presents an unself-conscious example of that social constructedness when he distinguishes between cultures and peoples capable of sympathy. He describes sympathy as a component of civilization, a product of historical progress, and thereby excludes marginal groups from what is essentially an elite society of sympathy. "Savages" and the laboring poor are in his view insensible to social or physical feeling and therefore incapable of sympathetic relations. Sympathy thus becomes an argument for social distinctions and for protecting elite society from the "coarsening" effects of labor. "Before we can feel much for others," Smith asserts, "we must in some measure be at ease ourselves." ${ }^{45}$ Smith's social sympathy, in effect, depends upon a careful calibration of comfort and distress. Proponents 
of clinical empathy must determine whether it is possible to create a paradigm that controls or mediates suffering without that mediation doing violence by distancing patients from a sympathetic elite. It is tempting to reject sympathy altogether on these grounds, and yet a wholesale rejection ignores the need for clinicians to recognize and work with their emotional responses to patients and to in some way distance themselves from patients' suffering. The limits of sympathy, as well as its possible abuses, do not preclude the possibility of face-to-face empathetic encounters that provide the physician with knowledge (however imperfect) and that provide the patient with connection (however imperfect).

\section{The Return to Empathy}

Smith's emphasis on an ethical practice of sympathy as at once enabled and limited by the imagination offers an important qualification to the practice of clinical empathy. It cautions physicians that they cannot disentangle themselves from their position of authority over patients. Because physicians and other health care practitioners wield the power of expertise and influence the patient's experience through prescribed treatments, it is essential that they recognize clinical empathy as ultimately a component of the medical technology and knowledge with which physicians manage patients. The dangers are clear: physicians who feel confident of their mastery of patient experience as medical knowledge may see themselves as empathic when that self-conception is in fact another mechanism of medical authority. Thinking that empathy is more first-person experiential knowledge than first-person observation, that "I am you" is a more ethical way of framing "I and you," risks denying the subjectivity and agency of the patient.

Renaissance scholar Stephen Greenblatt articulates a useful suspicion of the way that empathy masks the exercise of power. Empathy involves "insert[ing] oneself into the consciousness of another," he argues, and functions as a kind of "psychic mobility" that enables Western colonization of non-Western territories and societies. ${ }^{46}$ Greenblatt identifies power and improvisation as two important elements of empathy (both of which are relevant to the clinical encounter) and cautions against the "mystification of manipulation as disinterested empathy." He warns that the "imagined self-loss" of empathy in effect "conceals its opposite: a ruthless displacement and absorption of the other. Empathy, as the German Einfülung suggests, may be a feeling of oneself into an object, but that object may have to be drained of its own substance before it will serve as an appropriate vessel." ${ }^{47}$ The physician must guard against the potential for empathy to obscure or erase the patient's experience rather than to facilitate an ethical response to it. 
Even those health care practitioners who consciously privilege their patients' experiences find themselves caught in a knot of power relations. The physician is always in power in a medical context, and such power subsumes even deliberate attempts to displace authority by acknowledging the patient's subjectivity. Physicians must somehow contend with the barrier of authority, beginning with recognizing that the patient is the authority on her or his own experience of illness. Many physicians have themselves experienced illness or disability, which may equip them to imagine what the patient feels. Clinical empathy thus reframed as experience-based imaginative engagement suggests that the sick or disabled physician might be especially empathic. ${ }^{48}$ For example, physician and author Rachel Naomi Remen incorporates her longtime struggle with Crohn's Disease into a reconfiguration of the relation between doctor and patient. Without pretending to know patients fully or to share their darkest secrets, although dark secrets tend to emerge, she enters into a silent partnership as she works through what she calls "my own wounded healer, level-playing-field approach." ${ }^{\prime 9}$ However, when empathy for a patient depends on the physician's personal memories or feelings, it is necessary to recognize the danger of mere self-involvement, misreading the patient as a projection of the physician's necessarily limited and subjective experience. ${ }^{50}$

Future discussions of clinical empathy must resolve several issues, beginning with the need to recognize that empathy can be self-interested and even potentially harmful and that an ethical practice of empathy involves collaboration with an individual patient as well as action taken to relieve the patient's distress. These theories must also move beyond a reaction against the now outdated notion of "detached concern" and account for problems created in current reformulations where empathy depends on an imagined experience of the patient's suffering, which can easily lead to faulty assumptions about the patient. And when theories of empathy do advocate involving the patient in a collaborative account of illness, they must also address the power differential in the clinic and include a critique of the institutional structures that accord health care professionals so much power over patients. As Benbassat and Baumal and Claudia Johnson caution, feeling distress over another's suffering can be in itself the endpoint of empathy. To be ethical, clinical empathy must involve action, beginning with recognizing the broader social context of patients' health and well-being. With appropriate cautions, theories of clinical empathy should extend beyond the individual relation to address socially determined inequities in health care.

Medical educators who theorize and practice reflective writing and the study of literature need to proceed with similar caution, especially in regard to the problematic supposition that writing "from a patient's point of view" will develop empathy in medical students. And just as imagining 
the patient's perspective can diminish the patient's authority rather than provide insight, studying literature as a means of mediating the overwhelming impact of suffering can distract physicians and trainees from real suffering in the clinic. Adam Smith persuasively argues that aesthetic engagement cannot overcome the distance between fictive and actual experience. Readers, simply by closing the book, are always in control of calibrating the degree of distance and the intensity of engagement. Further, a consideration of the way that Smith reserves the practice of sympathy for a "civilized" elite raises the question of whether a complex understanding of sympathy, dependent on sophisticated engagements with theory and literature, is harmful in that it potentially excludes those who are less educated and/or simply less experienced with such practices. Finally, theorists who advocate an engagement with literature as a means of generating empathy must show how responses to and insights about literature transfer to the clinic. These problems represent not a dead end but rather a challenge to develop more sophisticated theories and practices of empathy. Critical theory and literary studies offer many resources for further formulations of empathy and related practices, especially as their insights inform the increased self-awareness and openness to discussion and criticism necessary for any ethical project.

Advocates of empathy in clinical practice and in medical education face serious challenges. Physicians are expected to master vast quantities of data-beginning with a trainee's first years in medical school and immersion in the "fund of knowledge." ${ }^{51}$ However, learning about the way an individual patient experiences and makes meaning from illness and the social context of that suffering is vastly different from the way students are tested on knowledge about the organ systems and disease. While students may seem to master knowledge of a first-person account or short story about illness, they must never assume mastery over knowledge of the patient. Theories of empathy must address tendencies to objectify the patient as a spectacle of suffering through which physicians exercise their own virtue. The responsibility that physicians bear in caring for patients is in itself a mode of power. The moral gravity of the patient who is vulnerable and in pain can be an instrument of power for any who attempts to ameliorate that pain, whether that be a literary studies scholar or physician. Further, theories of empathy that emphasize interpersonal relations should not obscure the larger social contexts that determine illness and disability, beginning with inequities in access to and quality of health care based on ethnicity, class, gender, and sexual/affectional orientation. These problems compel rather than discourage the development of sophisticated paradigms of empathy as a means of reframing the discussion of ethics in medical education and in clinical practice.

SUNY Upstate Medical University 


\section{NOTES}

1 On the tension between role modeling and the values taught in the classroom, see, e.g., F. W. Hafferty and R. Franks, "The Hidden Curriculum, Ethics Teaching, and the Structure of Medical Education," Academic Medicine 69, no. 11 (1994): 861-71. See also Jack Coulehan and Peter C. Williams, "Vanquishing Virtue: The Impact of Medical Education," Academic Medicine 76, no. 6 (2001): 598-605.

2 Sung Soo Kim, Stan Kaplowitz, and Mark V. Johnston, "The Effects of Physician Empathy on Patient Satisfaction and Compliance," Evaluation and the Health Professions 27, no. 3 (2004): 246; see also Donald A. Redemeier, Jean-Pierre Molin, and Robert J. Tibshirani, "A Randomised Trial of Compassionate Care for the Homeless in an Emergency Department," The Lancet 345, no. 8958 (1995): 1131-34. A typical article advocating empathic engagement states that " $[t]$ he effective use of empathy promotes diagnostic accuracy, therapeutic adherence, and patient satisfaction": John L. Coulehan, Frederic W. Platt, Barry Egener, Richard Frankel, Chen-Tan Lin, Beth Lown, and William H. Salazar, "Let Me See if I Have This Right . . ': Words That Help Build Empathy," Annals of Internal Medicine 135 (2001): 221.

3 Howard Spiro, "What Is Empathy and Can it Be Taught?" Annals of Internal Medicine 116 (1992): 844. For studies that suggest the decline in empathy in medical students, see, e.g., Ruth Elder, John Price, and Gail Williams, "Differences in Ethical Attitudes between Registered Nurses and Medical Students," Nursing Ethics 10 (2003): 149-64, and Mohammadreza Hojat, Joseph S. Gonnella, Salvatore Mangione, Thomas J. Nasca, J. Jon Veloski, James B. Erdmann, Clara A. Callahan, and Michael Magee, "Empathy in Medical Students as Related to Academic Performance, Clinical Competence and Gender," Medical Education 36, no. 6 (2002): 522-27.

4 Interestingly, Spiro describes students' internalization of what Foucault articulates as the "medical gaze" when he writes: "In clinical medicine, we talk mostly about the 'case' and not about the person; reports are written in the passive voice to imply that truth is being uncovered by an ineluctable force. . . . The eye is quicker than the ear; yet, the patient's experience is more complicated and variable than the disease visible to the doctor. Often the individual patient is seen as only a model, a body to be treated, or a good "teaching case' that illustrates a point." Spiro, "What Is Empathy," 844.

5 Jerome Lowenstein, "Can You Teach Compassion?" in The Midnight Meal and Other Essays About Doctors, Patients, and Medicine (New Haven, CT: Yale Univ. Press, 1997), 12-19.

6 Spiro, "What Is Empathy," 843.

7 Coulehan et al., "'Let Me See if I Have This Right,"” 221.

8 Jochanan Benbassat and Reuben Baumal, "What Is Empathy, and How Can it Be Promoted During Clinical Clerkships?” Academic Medicine 79, no. 9 (2004): 833.

9 Benbassat and Baumal, "What Is Empathy," 833.

10 Benbassat and Baumal, "What Is Empathy," 834. Jodi Halpern cites sadism as an example of an empathic enjoyment of another's suffering. See From Detached Concern to Empathy: Humanizing Medical Practice (New York: Oxford Univ. Press, 2001), 36n21.

11 See Halpern, From Detached Concern to Empathy, chap. 1.

12 Halpern, From Detached Concern to Empathy, 33 and 40.

13 See Michael S. Gazzaniga, The Ethical Brain (New York: Dana Press, 2005).

14 Jerome Lowenstein, "Can You Teach Compassion?" 16.

15 Larry R. Churchill, "Why Literature and Medicine?" Literature and Medicine 1 (1992; rev. ed.): $35-36$.

16 James N. Kirkpatrick, Kyle Nash, and Thomas P. Duffy, "Well Rounded," Archives of Internal Medicine 165, no. 6 (2005) 615.

17 Eric B. Larson and Xin Yao, "Clinical Empathy as Emotional Labor in the Patient-Physician Relationship," Journal of the American Medical Association 293, no. 9 (2005): 1102. 
18 Spiro, "What Is Empathy," 845.

19 Halpern, From Detached Concern to Empathy, 16.

20 Halpern, From Detached Concern to Empathy, 60.

21 Halpern, From Detached Concern to Empathy, 94 and 87. I suggest that one powerful and yet unexamined role that narrative plays in medicine is in the rhetorical effects of physicians' narrations of the success of their techniques.

22 Halpern, From Detached Concern to Empathy, 98n52.

23 On the other hand, Coulehan and coauthors acknowledge the problem of both patient alterity and the differential in power implicitly by emphasizing the need for collaboration with the patient on the basic elements of diagnosis. (The title of their essay begins with one of several suggested collaborative phrasings, "Let me see if I have this right.")

24 Halpern, From Detached Concern to Empathy, 88 and 90.

25 Spiro, "What Is Empathy," 843.

26 Halpern, From Detached Concern to Empathy, 73.

27 Jodi Halpern, "What Is Clinical Empathy?" Journal of General Internal Medicine 18, no. 8 (2003): 672.

28 Halpern, "What Is Clinical Empathy," 671.

29 Helen Deutsch, "Symptomatic Correspondences: The Author's Case in EighteenthCentury Britain," Cultural Critique 42 (1999): 37. Mullan portrays physicians such as George Cheyne linking themselves with novelists such as Richardson (who published Cheyne in addition to avidly corresponding with him) and establishing a shared sensibility and specialized mode of communication. John Mullan, Sentiment and Sociability: The Language of Feeling in the Eighteenth Century (Oxford: Clarendon Press, 1988), 207.

30 Examples of medical treatises dealing with sympathy are William Buchan's popular Domestic Medicine, first published in 1769, The English Malady, published in 1733 by George Cheyne, and Robert Whytt's 1751 Essay on the Vital and Other Involuntary Motions of Animals.

31 Deutsch describes this contradiction in her definition of sensibility as a "discourse that bridged literature and medical science in an era when they were diverging as professions [and] restored the body to life and to society, rendering it vulnerable, even ill, while allowing it to speak." Deutsch, "'This Monster, the Body': Narratives of Illness, Histories of Presence, 1812, 1993," in Monstrous Dreams of Reason: Body, Self, and Other in the Enlightenment, ed. Laura J. Rosenthal and Mita Choudhury (Lewisburg, PA: Bucknell Univ. Press, 2002), 113.

32 There were successful surgical therapies, such as amputating a gangrenous limb, and some useful pharmaceutical therapies, such as taking willow bark (the precursor to aspirin) for pain and fever. Midwifery was often successful in dealing with obstetrical difficulties during labor. But more often the therapies were dangerous-such as Benjamin Rush's prescriptions of mercury and jalap, a powerful purgative, for treating yellow fever-or simply futile, except perhaps in symbolic terms, such as Philadelphia officials' public health measure of firing cannons to disinfect the air during its remarkably deadly 1793 yellow fever epidemic.

33 William Cullen and his student John Brown, both eighteenth-century physicians, shaped theories of illness that depended on a notion of equilibrium that was either healthy or disturbed by an excess or a lack of stimulation. See Charles Singer and E. Ashworth Underwood, A Short History of Medicine (New York: Oxford Univ. Press, 1962), 148-49.

34 Encyclopaedia Britannica, 3rd edition, s.v. "Sensibility."

35 Whytt argued that "there is united to the bodies of men and animals an active, living, sentient principle." Robert Whytt, "An Essay on the Vital and other Involuntary Motions of Animals," in The Works of Robert Whytt, MD (London: T. Becket and P. A. Dehondt, 1768), 144. For an excellent discussion of Whytt, which informs my use of his work here, see Steven Bruhm, Gothic Bodies: The Politics of Pain in Romantic Fiction (Philadelphia: Univ. of Pennsylvania Press, 1994), chap. 1. 
36 Christopher Lawrence, "The Nervous System and Society in the Scottish Enlightenment," in Natural Order: Historical Studies of Scientific Culture, ed. Barry Barnes and Steven Shapin (Beverly Hills, CA: Sage, 1979), 25.

37 For Burke, literature and art provide distance from what would otherwise be overwhelming suffering, enabling the experience of sympathy and the formation of social bonds. For Hume, sympathy is more likely when the pain of others is mediated through the medium of taste, as an aesthetic response to literature and art. See Edmund Burke, $A$ Philosophical Enquiry into the Origin of Our Ideas of the Sublime and Beautiful, ed. J. T. Boulton (London: Routledge, 1958) and David Hume, "Of the Delicacy of Taste and Passion," in Essays, Moral, Political, and Literary, ed. Eugene F. Miller, Library of Economics and Liberty (Indianapolis, IN: Liberty Fund, 1987).

38 Claudia L. Johnson, Equivocal Beings: Politics, Gender, and Sentimentality in the 1790s: Wollstonecraft, Radcliffe, Burney, Austen (Chicago: Univ. of Chicago Press, 1995), 5.

39 Kathryn Montgomery Hunter, Rita Charon and John L. Coulehan, "The Study of Literature in Medical Education," Academic Medicine 70, no. 9 (1995): 794.

40 In the years prior to his famous 1776 argument for self-interested individualism within a free-market economy, The Wealth of Nations, Smith had taught and published on ethics and emotion.

41 See Adam Smith, The Theory of Moral Sentiments, ed. D. D. Raphael and A. L. Macfie, Glasgow Edition of the Works and Correspondence of Adam Smith (Indianapolis, IN: Liberty Fund, 1982), 9-10, and Lawrence, "The Nervous System and Society," 32.

42 Smith, The Theory of Moral Sentiments, 9.

43 Smith, The Theory of Moral Sentiments, 9.

44 Smith, The Theory of Moral Sentiments, 27.

45 Smith, The Theory of Moral Sentiments, 205. See Lawrence, "The Nervous System and Society," 28-31, on the relation between sensibility and civilization.

46 Stephen Greenblatt, Renaissance Self-Fashioning: From More to Shakespeare (Chicago: Univ. of Chicago Press, 1980), 227. Here Greenblatt is critiquing sociologist Daniel Lerner's concept of empathy as a characteristic of modern Western society in The Passing of Traditional Society: Modernizing the Middle East (New York: Macmillan, 1958). Nancy Roberts discusses Greenblatt's critique of empathy in her Schools of Sympathy: Gender and Identification through the Novel (Montreal: McGill-Queen's Univ. Press, 1997).

47 Greenblatt, Renaissance Self-Fashioning, 231 and 227.

48 The classic popular representation of the empathic physician is the 1991 film The Doctor, in which William Hurt plays an unfeeling surgeon who sees emotions and caring as antithetical to good medicine until he himself becomes ill.

49 Rachel Naomi Remen, Kitchen Table Wisdom: Stories That Heal (New York: Riverhead Books, 1996), 208.

50 Conversely we must ask how a physician maintains the necessary authority if she or he is understood by the patient to be suffering, a condition almost always understood as a sign of weakness and diminished capacities, as fantastic as the ideal of an infallible physician might be in reality.

51 The total sum of medical information now doubles, on average, every 3.5 years. Melissa M. Brown, Gary C. Brown, Sanjay Sharma, Evidence-Based to Value-Based Medicine (Chicago: AMA Press, 2005), 4. 